\title{
Nitrogen-Doped Carbon Nanotube/Polypropylene Composites with Negative Seebeck Coefficient
}

\author{
Beate Krause ${ }^{1}{ }^{(}$, Ioannis Konidakis ${ }^{2}$, Mohammad Arjmand ${ }^{3,+}{ }^{\oplus}$, Uttandaraman Sundararaj ${ }^{3}{ }^{2}$, \\ Robert Fuge ${ }^{4}$, Marco Liebscher ${ }^{5}(0)$, Silke Hampel ${ }^{4}{ }^{\circledR}$, Maxim Klaus ${ }^{1}$, Efthymis Serpetzoglou 2,6, \\ Emmanuel Stratakis ${ }^{2}$ (D) and Petra Pötschke ${ }^{1, *(1)}$ \\ 1 Leibniz-Institut für Polymerforschung Dresden e.V. (IPF), Hohe Str. 6, 01069 Dresden, Germany; \\ krause-beate@ipfdd.de (B.K.); maximklaus@gmx.net (M.K.) \\ 2 Foundation for Research and Technology-Hellas (FORTH), Institute of Electronic Structure and Laser (IESL), \\ P.O. Box 1385, 71110 Heraklion-Crete, Greece; ikonid@iesl.forth.gr (I.K.); eserpe@iesl.forth.gr (E.S.); \\ stratak@iesl.forth.gr (E.S.) \\ 3 Department of Chemical and Petroleum Engineering, University of Calgary, 2500 University Dr NW, \\ Calgary, AB T2N 1N4, Canada; mohammad.arjmand@ubc.ca (M.A.); u.sundararaj@ucalgary.ca (U.S.) \\ 4 Leibniz-Institut für Festkörper- und Werkstoffforschung Dresden (IFW), Helmholtzstraße 20, 01069 Dresden, \\ Germany; robert.fuge@gmx.de (R.F.); s.hampel@ifw-dresden.de (S.H.) \\ 5 Institut für Baustoffe, Technische Universität Dresden, 01062 Dresden, Germany; \\ marco.liebscher@tu-dresden.de \\ 6 Department of Physics, University of Crete, 71003 Heraklion-Crete, Greece \\ * Correspondence: poe@ipfdd.de; Tel.: +49-351-4658-395 \\ + Present address: School of Engineering, University of British Columbia, Kelowna, BC V1V 1V7, Canada.
}

Received: 16 December 2019; Accepted: 17 January 2020; Published: 28 January 2020

\begin{abstract}
This study describes the application of multi-walled carbon nanotubes that were nitrogen-doped during their synthesis (N-MWCNTs) in melt-mixed polypropylene (PP) composites. Different types of N-MWCNTs, synthesized using different methods, were used and compared. Four of the five MWCNT grades showed negative Seebeck coefficients $(S)$, indicating n-type charge carrier behavior. All prepared composites (with a concentration between 2 and $7.5 \mathrm{wt} \% \mathrm{~N}-\mathrm{MWCNTs}$ ) also showed negative $S$ values, which in most cases had a higher negative value than the corresponding nanotubes. The $S$ values achieved were between $1.0 \mu \mathrm{V} / \mathrm{K}$ and $-13.8 \mu \mathrm{V} / \mathrm{K}$ for the N-MWCNT buckypapers or powders and between $-4.7 \mu \mathrm{V} / \mathrm{K}$ and $-22.8 \mu \mathrm{V} / \mathrm{K}$ for the corresponding composites. With a higher content of N-MWCNTs, the increase in electrical conductivity led to increasing values of the power factor $(P F)$ despite the unstable behavior of the Seebeck coefficient. The highest power factor was achieved with $4 \mathrm{wt} \% \mathrm{~N}-\mathrm{MWCNT}$, where a suitable combination of high electrical conductivity and acceptable Seebeck coefficient led to a $P F$ value of $6.1 \times 10^{-3} \mu \mathrm{W} /\left(\mathrm{m} \cdot \mathrm{K}^{2}\right)$. First experiments have shown that transient absorption spectroscopy (TAS) is a useful tool to study the carrier transfer process in CNTs in composites and to correlate it with the Seebeck coefficient.
\end{abstract}

Keywords: polypropylene; nitrogen doping; carbon nanotube; thermoelectric

\section{Introduction}

The transformation of thermally wasted energy into an induced voltage, according to the Seebeckor thermoelectric (TE) effect, is a very attractive approach to contribute to higher energy efficiency [1-3]. Hereby, the TE material performance is assessed by the temperature-dependent figure of merit 
$Z T$, which is determined by the Seebeck coefficient $S$, the electrical conductivity $\sigma$ and the thermal conductivity $\kappa$. The Seebeck coefficient $S$ is calculated by

$$
S=\frac{U}{d T}
$$

where $U$ is measured thermovoltage at a temperature difference $d T$. A negative Seebeck coefficient indicates an n-type material and a positive Seebeck coefficient signifies a p-type material. The power factor $(P F)$ is commonly used as a performance value since it is directly related to the usable power that can be achieved. $P F$ is calculated as follows:

$$
P F=S^{2} \sigma
$$

where $S$ is the Seebeck coefficient and $\sigma$ is the electrical conductivity. The dimensionless figure of merit $\mathrm{ZT}$ is defined as

$$
Z T=\frac{S^{2} \sigma}{\kappa} T
$$

where $S$ is the Seebeck coefficient, $\sigma$ is the electrical conductivity, $T$ is the temperature and $\kappa$ is the thermal conductivity. To achieve high TE performance, high Seebeck coefficient $S$, high electrical conductivity $\sigma$, and low thermal conductivity $\kappa$ are desirable. However, these parameters are heavily interrelated, and the optimization is a challenge.

Compared to already used and established semiconducting material compounds [4], new TE materials based on intrinsically conductive polymer composites (ICPs) and composites of insulating polymers modified with electrically conductive fillers (CPCs) [5] are becoming increasingly important. The advantages of thermoplastic-based melt-prepared CPCs are their low cost, adaptable mechanical properties, and versatile design options. In addition, CPCs intrinsically have a low thermal conductivity, which contributes greatly to an effective TE material.

For preparing low cost and effective CPCs, carbon nanotubes (CNTs) are efficient electrically conductive fillers, due to their high aspect ratio and high electrical conductivity. In a polymer matrix, a CNT network allows an electron (n-doping) or hole (p-doping) transport by tunneling and hopping mechanisms. Typically, CNTs exhibit p-type behavior due to oxygen moieties withdrawing electrons to create holes. Therefore, an increased oxygen content of the CNTs, e.g., through functionalization leads to higher positive Seebeck coefficients [6-8]. A versatile approach to further adapt the electronic properties of CNTs and thus improve the thermoelectric properties of CNT/polymer nanocomposites is the doping of the hexagonal $s p^{2}$-hybridized structure. Theoretical and experimental studies have shown that the electronic properties of CNTs can be regulated by incorporating foreign atoms in their molecular structure [9-11].

The n-type doping of CNTs is challenging, especially in terms of stability. Different approaches for CNT-doping are described, such as CNT functionalization, polymer wrapping, charge transfer from a polymer matrix to the CNTs, encapsulation of organometallic materials within the nanotubes, doping by salt anions with counter cations, or heteroatom incorporation into the CNT walls [11-16]. Concerning the stability of the doping, further processing such as annealing, purification or incorporation into polymer matrices also plays an important role. Nitrogen $(\mathrm{N})$, due to its size proximity to carbon and its electron configuration, is an excellent choice for a heteroatom to adjust the electronic properties of CNTs. Theoretical calculations have shown that nitrogen-doped CNTs (N-CNTs) can be p-type and n-type semi-conductors depending on different parameters such as diameter, chirality, nitrogen content, and bonding type [17,18]. Since nitrogen has an additional electron compared to carbon, the direct replacement of carbon atoms by nitrogen in the CNT structure results in an n-type material with localized states above the Fermi level. In this case, there is an excess of electron donors through the $\mathrm{N}$-rich area of CNTs, which guarantees the n-type behavior [17]. On the other hand, nitrogen doping can also generate defects through the tubular structure of CNTs, which may result in the rearrangement of the neighboring carbon atoms, like structural gaps or 5- or 7-member-rings instead of 6-member-rings 
due to pyridinic-bonded and pyrrolic-bonded nitrogen [19-22]. The electronic behavior then depends on the new geometry of CNTs. In this scenario, p-type behavior might be observed for nitrogen-doped CNTs. Using tight-binding and ab-initio calculations, Czerw et al. [23] assumed that the pyridinic configuration of nitrogen atoms is responsible for the change from semiconducting to metallic and from $\mathrm{p}$ - to n-type behavior during nitrogen doping. Kang and Jeong [24] suggested from total energy calculations that the pyridinic configuration proposed by Czerw et al. [23] is energetically favorable. However, they suggested that the p-type behavior of nitrogen-doped CNTs is attributed to the lone-pair electrons of nitrogen atoms. Later, this theory was adopted by other researchers to explain the p-type behavior of CNTs [25].

A very attractive approach to obtain n-type materials by doping carbon structures with nitrogen is, therefore, the direct incorporation into the hexagonal carbon lattice of the nanotube walls during the synthesis process, e.g., in chemical vapor deposition [26,27], which is scalable and saves time and costs. This is also a suitable way to reach long-term stable n-doped nanotubes. As mentioned above, this doping of CNTs with nitrogen changes the CNT morphology and therefore the properties. Due to the configuration of the nitrogen, it acts as an electron donor that drastically changes the semiconducting behavior of the CNTs. The CNTs may change from a p-type hole conductor to an n-type electron conductor, which is reflected by a negative Seebeck coefficient. Moreover, the increase in charge carrier density also leads to the increased electrical conductivity of the CNTs. This makes N-doped CNTs a promising candidate for various applications like field emission tips or lithium storage [28,29].

Furthermore, nitrogen doping can also change the surface properties [17-20] of the nanotube walls, and thus, can enhance the dispersibility of CNTs, e.g., in water-based solvents. In general, pristine CNTs exhibit a hydrophobic surface [30], whereas doped N-CNTs have more chemically active sites, which facilitate electron transfer and enhance the surface polarity of the N-CNTs, resulting in a better wettability of polar solvents and polymers.

Transient absorption spectroscopy (TAS) is a powerful technique and a figure-of-merit method to explore ultrafast phenomena and relaxation processes that take place within a wide range of materials. For instance, it is widely used for studying components of photovoltaic devices [31-33], 2D materials [34,35], inorganic glasses [36], and single-walled carbon nanotubes wrapped with polymers [37-40]. For energy conversion materials, in particular, TAS provides important insights on the excitation dynamics and free charge carrier lifetimes, which are crucial for the efficiency of energy conversion processes.

Polypropylene (PP) is a commonly used thermoplastic material from which TE materials have already been derived. Luo et al. [41-44] described TE results on melt-prepared polypropylene (PP)/single-walled CNT (SWCNT) composites and obtained Seebeck coefficients between 25 and $34 \mu \mathrm{V} / \mathrm{K}\left(0.8-6.0 \mathrm{wt} \%\right.$ SWCNT type Tuball). The highest power factor was found at $0.066 \mu \mathrm{W} / \mathrm{m} \cdot \mathrm{K}^{2}$ (4 wt\% SWCNT Tuball) [42]. A Seebeck coefficient of $35.6 \mu \mathrm{V} / \mathrm{K}$ and a power factor of $0.01 \mu \mathrm{W} / \mathrm{m} \cdot \mathrm{K}^{2}$ were described in [41] for PP/2 $\mathrm{wt} \%$ SWCNT composite. The addition of an ionic liquid to a PP/SWCNT composite leads to higher Seebeck values and power factor [43]. Furthermore, Luo et al. reported an easy way to generate an n-type PP composite by adding polyethylene glycol $[41,44]$ or polyoxyethylene 20 cetyl ether during the melt-mixing process of PP with SWCNTs [44]. Hereby, values of up to $-56 \mu \mathrm{V} / \mathrm{K}$ were achieved, and the composites remain with a negative Seebeck coefficient after being exposed to air for eight months [41]. By using PP based p-and n-type composites, they were able to prepare a demonstrator of a TE generator, which generated with 49 leg pairs a thermovoltage of $110 \mathrm{mV}$ at $70 \mathrm{~K}$ temperature difference. Another way to generate n-type PP composites was described recently by Paleo et al. [45], who incorporated 1 to $5 \mathrm{wt} \%$ carbon nanofibers into a PP matrix and reported Seebeck coefficients of about $-8.5 \mu \mathrm{V} / \mathrm{K}$.

To extend the possibilities to obtain stable n-type PP composites without liquid additives, in this work, different kinds of nitrogen-doped multi-walled carbon nanotubes were incorporated in PP by melt compounding. The thermoelectric properties of such PP/N-MWCNT composites were compared at different $\mathrm{CNT}$ contents and different measurement temperatures. In addition, the 
n-type PP/N-MWCNT composites were compared with p-type PP/CNT composites. Furthermore, the thermoelectric properties of the composites were compared to the thermoelectric properties of the corresponding CNT powders. TAS measurements on the composites were performed to investigate the exciton dynamics of the polypropylene composites and correlated with the Seebeck coefficient.

\section{Materials and Methods}

Polypropylene (PP) of the type Moplen HP 400R (LyondellBasell Industries, Rotterdam, The Netherlands) with a melt flow rate of $25 \mathrm{~g} / 10 \mathrm{~min}$ at $230^{\circ} \mathrm{C}, 2.16 \mathrm{~kg}$ was used as a polymer matrix.

Different nitrogen-doped multi-walled carbon nanotubes (N-MWCNT) were studied as electrically conductive filler material. The first group was synthesized at the University of Calgary, Canada using a chemical vapor deposition (CVD) setup described in [22]. The synthesis temperature was set at $750{ }^{\circ} \mathrm{C}$. Catalyst, synthesis time, and gas flow rate of ethane, ammonia (as nitrogen-precursor), and argon $[22,46]$ were varied according to Table 1 . Selected properties of the synthesized N-MWCNTs are shown in Table 1 and described in [22,46] in which also transmission electron microscopy (TEM) images of the MWCNTs are shown. Samples A1-A3 produced with iron as catalyst show bamboo-like configurations with a certain surface roughness resulting from the imperfect interconnection of the bamboo-like compartments, whereas samples A4 produced with cobalt as catalyst mainly show open-channel tubes.

Table 1. Synthesis conditions and selected properties of N-doped multi-walled carbon nanotubes (MWCNTs) prepared using chemical vapor deposition (CVD) [22,46].

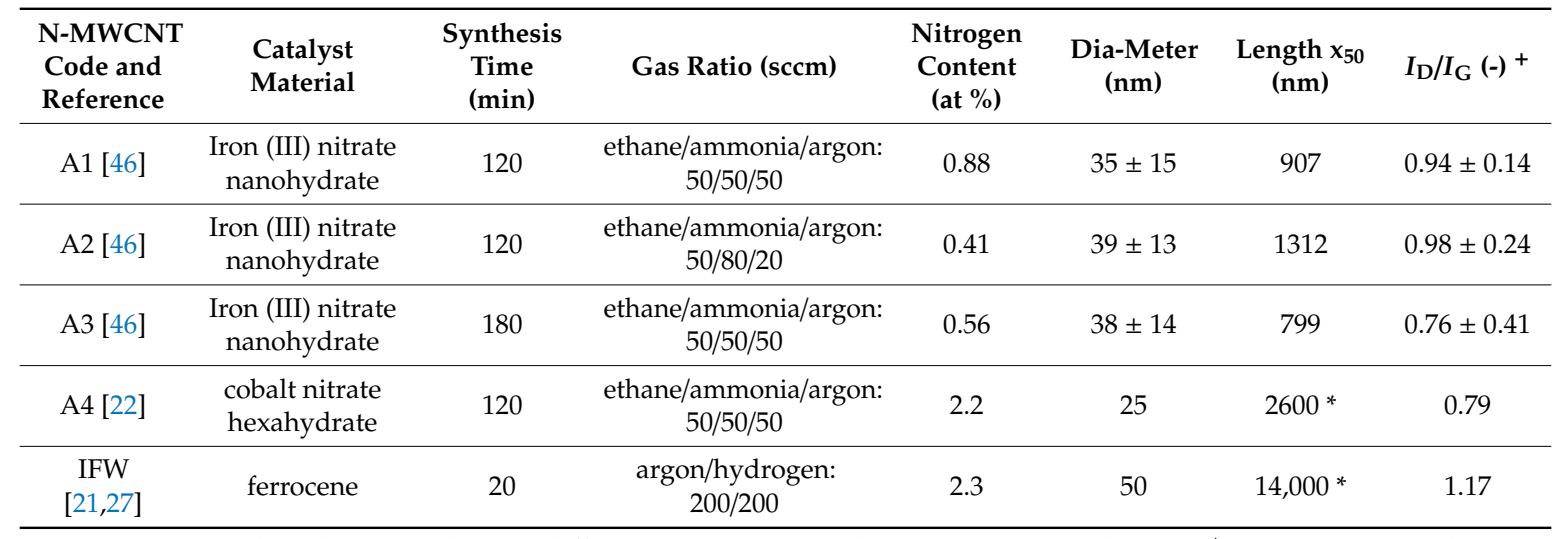

* Average value, determined using different preparation and measurement conditions. ${ }^{+} I_{D} / I_{G}$ represents the intensity ratio of the $\mathrm{D}$ and $\mathrm{G}$ band in Raman investigations.

The second type of N-MWCNT (IFW) was synthesized at the Leibniz Institute for Solid State and Materials Research Dresden (IFW), Dresden, Germany, in the shape of CNT carpets via an Aerosol Assisted Chemical Vapor Deposition System (AACVD) using acetonitrile (synthetic grade, Merck, Darmstadt, Germany) as nitrogen-precursor, as described in [21]. Further details, including TEM images showing the bamboo-like structure, are given in [21,27].

For comparison and to explain the role of nitrogen doping, three different undoped carbon nanotubes were used. Multi-walled carbon nanotubes (MWCNT) NC7000 (Nanocyl ${ }^{\mathrm{TM}}$, Sambreville, Belgium, [47]) produced in an industrial large-scale catalytic vapour deposition process with an average diameter of $10 \mathrm{~nm}$, average length of $1.3 \mu \mathrm{m}$ [48,49], carbon purity of $90 \%$, surface area of 250-300 $\mathrm{m}^{2} / \mathrm{g}$ [50], and a density of $1.75 \mathrm{~g} / \mathrm{cm}^{3}$ were used as the first type. MWCNTs CNS-PEG, Carbon NanoStructure (CNS) flakes covered with polyethylene glycol (PEG) to enhance the wettability of CNS by non-polar polymers like PP (Applied NanoStructured Solutions LLC, Baltimore, MD, USA), were used as the second type. The CNS-PEG nanotubes have a mean diameter of $14 \pm 4 \mathrm{~nm}$, an average number of 4 walls, average length of $70 \mu \mathrm{m}$, a purity of $>97 \%$, and a bulk density of $0.135 \mathrm{~g} / \mathrm{cm}^{3}$ [51]. Additionally, single-walled CNTs (SWCNTs) of the type Tuball ${ }^{\mathrm{TM}}$ grade $75 \%$ (OCSiAl 
S.a.r.1., Luxembourg, [52]) having a mean diameter of $1.6 \mathrm{~nm}$, a length exceeding $5 \mu \mathrm{m}$ [53], a bulk density of $0.09 \mathrm{~g} / \mathrm{cm}^{3}$ [54], and surface area of $331 \mathrm{~m}^{2} / \mathrm{g}$ [54] were used as the third type.

Buckypapers of the different CNTs were produced by dispersing $125 \mathrm{mg}$ CNTs in $100 \mathrm{~mL}$ chloroform via 10 min of ultrasonic treatment (UP400S, Hielscher Ultrasonics $\mathrm{GmbH}$, Teltow, Germany; 60\% amplitude, cycle 1 , sonotrode H3). The obtained dispersions were placed on a polytetrafluoroethylene (PTFE) filter (Ahlstrom Cooperation, Helsinki, Sweden, no. 760150, pore size $1.2 \mu \mathrm{m}$ ). Subsequently, the buckypapers were dried at $40^{\circ} \mathrm{C}$ in an oven and then removed from the filter support.

Melt mixing of PP nanocomposites was performed in a small-scale conical twin-screw micro compounder DSM 15 (Xplore, Sittard, The Netherlands) having a volume of $15 \mathrm{ccm}$ using a mixing temperature of $210^{\circ} \mathrm{C}$, a rotation speed of $250 \mathrm{rpm}$ and mixing time of $5 \mathrm{~min}$. The strands extruded from a die with $2 \mathrm{~mm}$ diameter were cut into pieces and compressing molded to plates with a diameter of 60 $\mathrm{mm}$ and a thickness of $0.5 \mathrm{~mm}$. For this, a hot press PW40EH (Paul-Otto-Weber GmbH, Remshalden, Germany) at $210{ }^{\circ} \mathrm{C}$ was used for $2 \mathrm{~min}$, and subsequent the sample was cooled using a minichiller for $30 \mathrm{~s}$. Strips were cut from the plates to measure electrical resistance and thermoelectric properties. Thin transparent layers (approx. $40 \mu \mathrm{m}$ ) were pressed using the same conditions for the TAS measurements.

For the evaluation of the MWCNT macrodispersion, transmission light microscopy (LM) was performed on the extruded composite strands with $2 \mathrm{wt} \% \mathrm{~N}$-MWCNT. Therefore, thin sections with a thickness of $5 \mu \mathrm{m}$ were prepared using a Leica RM2265 (Leica MikrosystemeVertrieb GmbH, Bensheim, Germany) at room temperature. The cut films were fixed on glass slides using the aqueous mounting medium Aquatex ${ }^{\circledR}$ (Sigma-Aldrich, Steinheim, Germany). The LM investigations were performed with a microscope BX53M combined with a camera DP71 (Olympus Deutschland GmbH, Hamburg, Germany). The agglomerate area ratio $\mathrm{A}_{\mathrm{A}}(\%)$, defined as the ratio between the area of filler agglomerates and the total area of the imaged sample, was calculated to quantify the remaining MWCNT agglomerates in the PP composite.

The Seebeck coefficient $(S)$ and volume resistivity were determined using the in-house equipment TEG at Leibniz-IPF and the methodology described in $[55,56]$. The measurements were performed at $40{ }^{\circ} \mathrm{C}$ with temperature differences between the two copper electrodes up to $8 \mathrm{~K}$. For the measurements on composites and buckypapers, the samples were painted with conductive silver at the ends to improve the electrical contact to the copper electrodes. Since it was not possible to produce stable free-standing buckypapers for all CNT types, TE measurements were also carried out on CNT powders. For the measurement of powders, the CNTs were filled in a poly(vinylidene fluoride) (PVDF) tube (inner diameter $3.8 \mathrm{~mm}$ ) and closed with copper plugs [57]. This double T-shaped specimen was clamped between the copper electrodes of the measurement device. Depending on the kind of CNTs and their bulk density, $0.01-0.04 \mathrm{~g}$ powder was used. The volume resistivity was measured with the same equipment using a four-wire technique. The measurement of thermovoltage and electrical resistance was performed using a multimeter DMM2001 (Keithley Instruments, Cleveland, OH, USA). The experiments were conducted in triplicate. The Figure of merit $Z T$ was calculated using a value of the thermal conductivity of PP composites of $0.28 \mathrm{~W} /(\mathrm{m} \cdot \mathrm{K})$, which was obtained in many pre-investigations as a proper mean value of PP filled with a low CNT content (between 0 and $5 \mathrm{wt} \%$ ) [51,58,59].

TAS measurements were performed on a Newport (TAS-1) transient absorption spectrometer (Newport Corporation, Irvine, CA, USA), which is shown schematically in Figure S2 in [33]. The experimental set up was explained in detail elsewhere [31-33]. For the measurements of the present study, the employed light source was a Yb:KGW pulsed laser with the central wavelength at $1026 \mathrm{~nm}$, a pulse duration of $170 \mathrm{fs}$, and a repetition rate of $1 \mathrm{KHz}$. The excitation of the composite samples occurred via two-photon absorption process, while the detection range was set between 550 and 910 $\mathrm{nm}$. All TAS measurements were performed on very thin pressed films at room temperature with a pump effluence of $14.7 \mathrm{~mJ} / \mathrm{cm}^{2}$. 


\section{Results}

\subsection{Thermoelectric Properties}

\subsubsection{Measurements at $40^{\circ} \mathrm{C}$}

Generally, n-doping or electron donation should improve electrical conductivity and n-type semi-conducting behavior. For the first group of N-MWCNTs (A1-A4), the thermoelectric results of their composites with $5 \mathrm{wt} \%$ loading are presented in Figure 1. As expected, the Seebeck coefficient $S$ is negative for all PP composites and varies between $-22.8 \mu \mathrm{V} / \mathrm{K}$ (N-MWCNT A2) and $-4.7 \mu \mathrm{V} / \mathrm{K}$ (N-MWCNT A4). The nitrogen atoms, incorporated into the hexagonal carbon lattice, act as electron donor not only in the pure nanotubes, but also in their PP composites. Therefore, a semiconducting composite behavior of type $\mathrm{n}$ is present, i.e., electron conduction is induced by a temperature gradient, which leads to a negative Seebeck coefficient. Interestingly, there is no clear correlation between the nitrogen content and the Seebeck coefficient or electrical conductivity, suggesting that other structural parameters of the nanotubes and their dispersion state in the composite likely play a role in the TE properties. Hence, the given results indicate a different electron configuration for the different nitrogen-doped CNTs. In addition, the samples with the higher Seebeck coefficient do not simultaneously show higher electrical conductivity. Despite the expectation that higher nitrogen content leads to higher (absolute) Seebeck coefficients and higher electrical conductivity $\sigma$, the comparison of the selected CNT types shows that the sample with the lowest nitrogen content (N-MWCNT A2) showed the highest negative Seebeck coefficient, but the lowest electrical conductivity. Instead, the highest values were measured for electrical conductivity $\sigma$ and thus also the highest power factor $P F$ as well as the figure of merit ZT for PP filled with N-MWCNT A1 (intermediate nitrogen content). The lowest negative Seebeck coefficient $(-4.7 \mu \mathrm{V} / \mathrm{K})$ for the PP composite was achieved with the incorporation of N-MWCNT A4, which is discussed in more detail in Section 3.3.

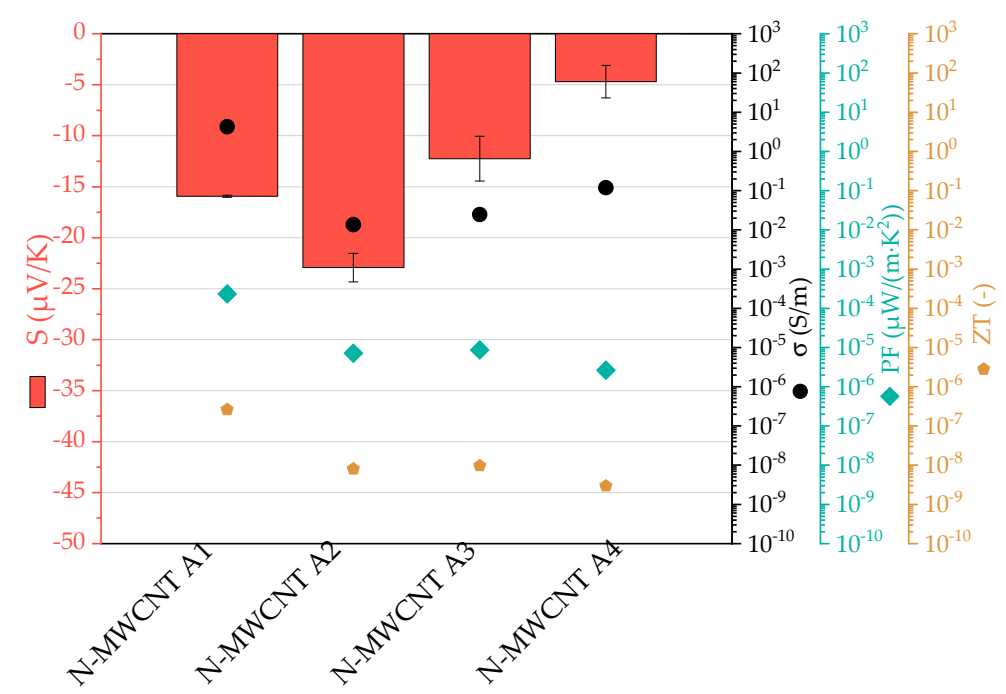

Figure 1. Thermoelectric properties $\left(40^{\circ} \mathrm{C}\right)$ of polypropylene $(\mathrm{PP}) / 5 \mathrm{wt} \%$ nitrogen-doped multi-walled carbon nanotubes (N-MWCNT) composites filled with different kinds of N-MWCNT (listed in Table 1).

Furthermore, PP composites with different concentrations of N-MWCNT A1 were produced and investigated for their thermoelectric properties (Figure 2). The sample with $2 \mathrm{wt} \% \mathrm{~N}-\mathrm{MWCNT}$ A1 gives a Seebeck coefficient of $-17.3 \pm 0.4 \mu \mathrm{V} / \mathrm{K}$, whereas, at $7.5 \mathrm{wt} \%$, only $-8.7 \pm 0.1 \mu \mathrm{V} / \mathrm{K}$ was measured. However, with increasing N-MWCNT A1 content, the electrical conductivity $\sigma$ of the samples increased, resulting in higher power factors $P F$, and figures of merit ZT. At PP/7.5 wt\% N-MWCNT A1, an electrical conductivity of $1.5 \mathrm{~S} / \mathrm{m}$, a power factor of $1.1 \times 10^{-4} \mu \mathrm{W} /\left(\mathrm{m} \cdot \mathrm{K}^{2}\right)$ and a $Z T$ value of $1.2 \times 10^{-7}$ were reached. 


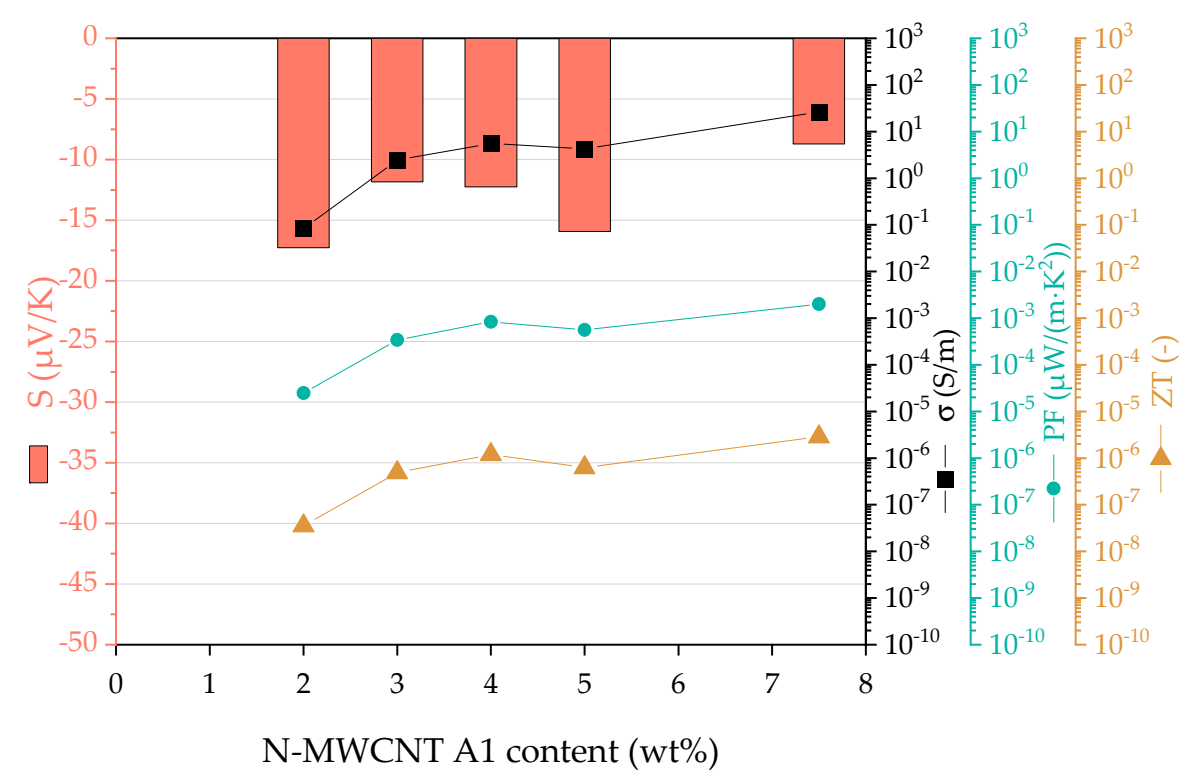

Figure 2. Thermoelectric properties $\left(40{ }^{\circ} \mathrm{C}\right)$ of $\mathrm{PP} / \mathrm{N}-\mathrm{MWCNT}$ A1 composites at different nanotube contents.

The second type of nitrogen-doped MWCNT, namely N-MWCNT IFW was incorporated in PP as well. The obtained thermoelectric properties of these composites are summarized in Figure 3. Here the Seebeck coefficient was almost constant at $-10 \mu \mathrm{V} / \mathrm{K}$ for the composites with contents of N-MWCNT IFW between $1.5 \mathrm{wt} \%$ and $4 \mathrm{wt} \%$. However, with increasing CNT content, the electrical conductivity increased up to $64 \mathrm{~S} / \mathrm{m}$ at $4 \mathrm{wt} \% \mathrm{CNT}$. Therefore, the values for the power factor and $\mathrm{ZT}$ increase with the CNT loading from $2.7 \times 10^{-4} \mu \mathrm{W} /\left(\mathrm{m} \cdot \mathrm{K}^{2}\right)$ up to $6.1 \times 10^{-3} \mu \mathrm{W} /\left(\mathrm{m} \cdot \mathrm{K}^{2}\right)$ and from $3.0 \times 10^{-7}$ to $6.8 \times 10^{-6}$, respectively. The high electrical conductivity of the samples is explained by the relatively high nitrogen content of these CNTs [27], their relatively high length [21], as well as their good state of dispersion (cf. Section 3.2).

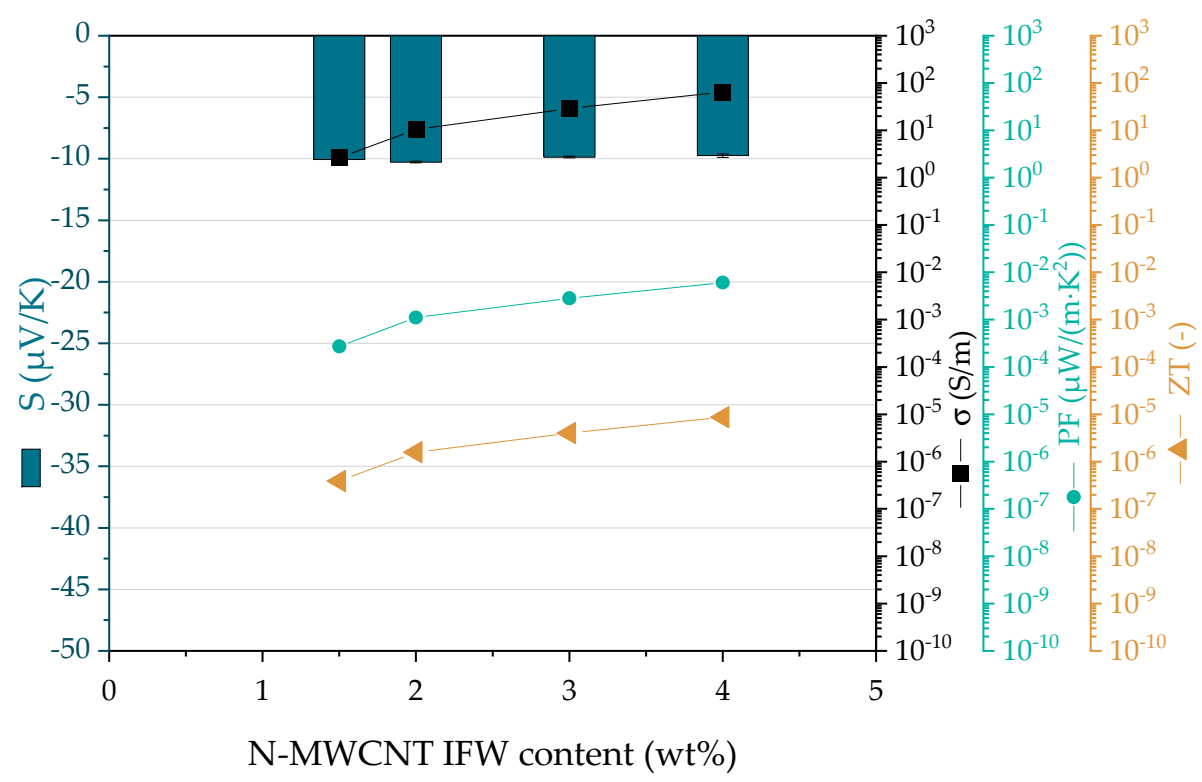

Figure 3. Thermoelectric properties of PP/N-MWCNT IFW composites at different nanotube contents.

A comparison of the two N-MWCNT types was performed by comparing the values of PP composites filled with N-MWCNT A1 or N-MWCNT IFW. Despite the lower (negative) value of the sample with PP/N-MWCNT IFW, due to its higher electrical conductivity, this material showed a 
higher $P F$ value at $6.1 \times 10^{-3} \mu \mathrm{W} /\left(\mathrm{m} \cdot \mathrm{K}^{2}\right)$ compared to $8.4 \times 10^{-4} \mu \mathrm{W} /\left(\mathrm{m} \cdot \mathrm{K}^{2}\right)$ for the PP/N-MWCNT A1 composite.

\subsubsection{Measurements at Elevated Temperatures}

As in practical applications, TE materials are exposed to different temperatures, the temperature dependence was studied using measuring temperatures of 60,80 , and $100^{\circ} \mathrm{C}$. The results are shown in Figure 4. At the same CNT content, it was found that the thermoelectric effect increases slightly with temperature, while the electrical conductivity remains almost constant (Table S1). The absolute values of composite materials based on N-MWCNT IFW increase on average with a coefficient of $0.3 \mu \mathrm{V} / \mathrm{K}$ per $10 \mathrm{~K}$ increase in the measurement temperature, while the increase of N-MWCNT A1 composite materials is lower with approximately $0.025 \mu \mathrm{V} / \mathrm{K}$ per $10 \mathrm{~K}$. With increasing temperature, the electrons or charge carriers possess a higher energy and hence higher mobility. With this higher energy of the electrons, the conduction mechanism changes to a thermally activated hopping. According to the so-called Mott variable range hopping (VRH) model, the electrons jump from one starting point to another with the lowest possible hopping energy, which is reflected in a slight increase in the Seebeck coefficient [60]. Kumanek et al. [11] described temperature-dependent thermoelectric measurements on ethyl cellulose/doped CNT films in a range from $30{ }^{\circ} \mathrm{C}$ to $100{ }^{\circ} \mathrm{C}$ and reported a nearly constant Seebeck coefficient of around $-20 \mu \mathrm{V} / \mathrm{K}$. In our study, only a marginal but visible temperature influence on the Seebeck coefficient could be found within the investigated temperature range.
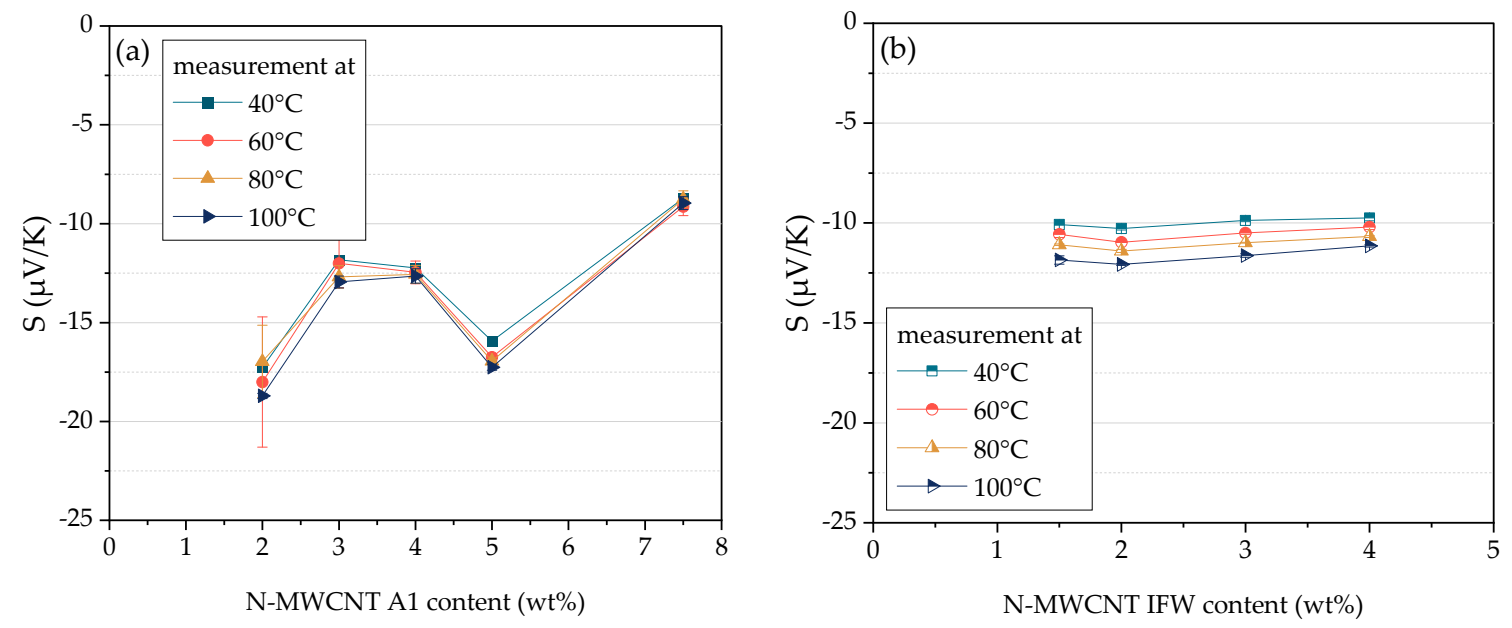

Figure 4. Seebeck coefficient of (a) PP/N-MWCNT A1 and (b) PP/N-MWCNT IFW composites at different nanotube contents measured at different temperatures.

3.2. Macrodispersion of Nitrogen-Doped Multi-Walled Carbon Nanotubes (N-MWCNT) in Polypropylene (PP) Composites

It is well-known that the dispersion of the conductive fillers in a polymer matrix plays an important role in the electrical properties [61]. In addition, it can be expected but has not yet been investigated, that the dispersion state in composites also influences the Seebeck coefficient. Even if, in addition to the electrical conductivity of the nanotubes themselves, it is mainly the conductive network formation on the nanoscale that determines the electrical conductivity, the dispersion state on the macroscale can provide information about which part of the added nanotubes can contribute to such network formation. With better CNT macrodispersion, more CNTs can participate in conductive network formation, which (if the CNTs are not otherwise different or altered, e.g., by shortening) can lead to higher electrical conductivity. As different N-MWCNT-A types were used, their state of dispersion in the PP matrix may be different. Thus, the nanotube macrodispersion was characterized for selected N-MWCNT composites using transmission light microscopy on thin sections (Figure 5). At a loading of $2 \mathrm{wt} \%$, the PP composites filled with N-NWCNT A1 and N-MWCNT IFW show well-dispersed 
MWCNTs. The quantitative evaluation resulted in agglomerate area ratios $\mathrm{A}_{\mathrm{A}}$ of $0 \%$ and $0.1 \%$ and only very small agglomerates are visible. The dispersion seems to be significantly better than that reported in [46] for composites of $2 \mathrm{wt} \% \mathrm{~N}-\mathrm{MWCNTs}$ in PVDF, where the same characterization procedure was used. In PVDF, considerably larger agglomerates were visible than in PP. At 5 wt $\%$ loading, the comparison between the dispersion of N-MWCNTs type A again shows a good macrodispersion for N-MWCNT A1, while N-MWCNT A2, A3, and A4 show a higher number of remaining agglomerates and $\mathrm{A}_{\mathrm{A}}$ values between $1.3 \%$ and $3.2 \%$. This poorer CNT macrodispersion is also reflected in lower electrical conductivity values than in the sample with N-MWCNT A1 (see Figure 1). Even though the sample N-MWCNT A4 with the highest nanotube aspect ratio (see Table 1) has the highest agglomerate area ratio $\mathrm{A}_{\mathrm{A}}$ of all composites with $5 \mathrm{wt} \%$ loading, there is no clear correlation between the aspect ratio and the macrodispersion. In addition, no direct relationship can be found between the state of the macrodispersion and the electrical conductivity or Seebeck coefficient when using the various N-MWCNT materials.
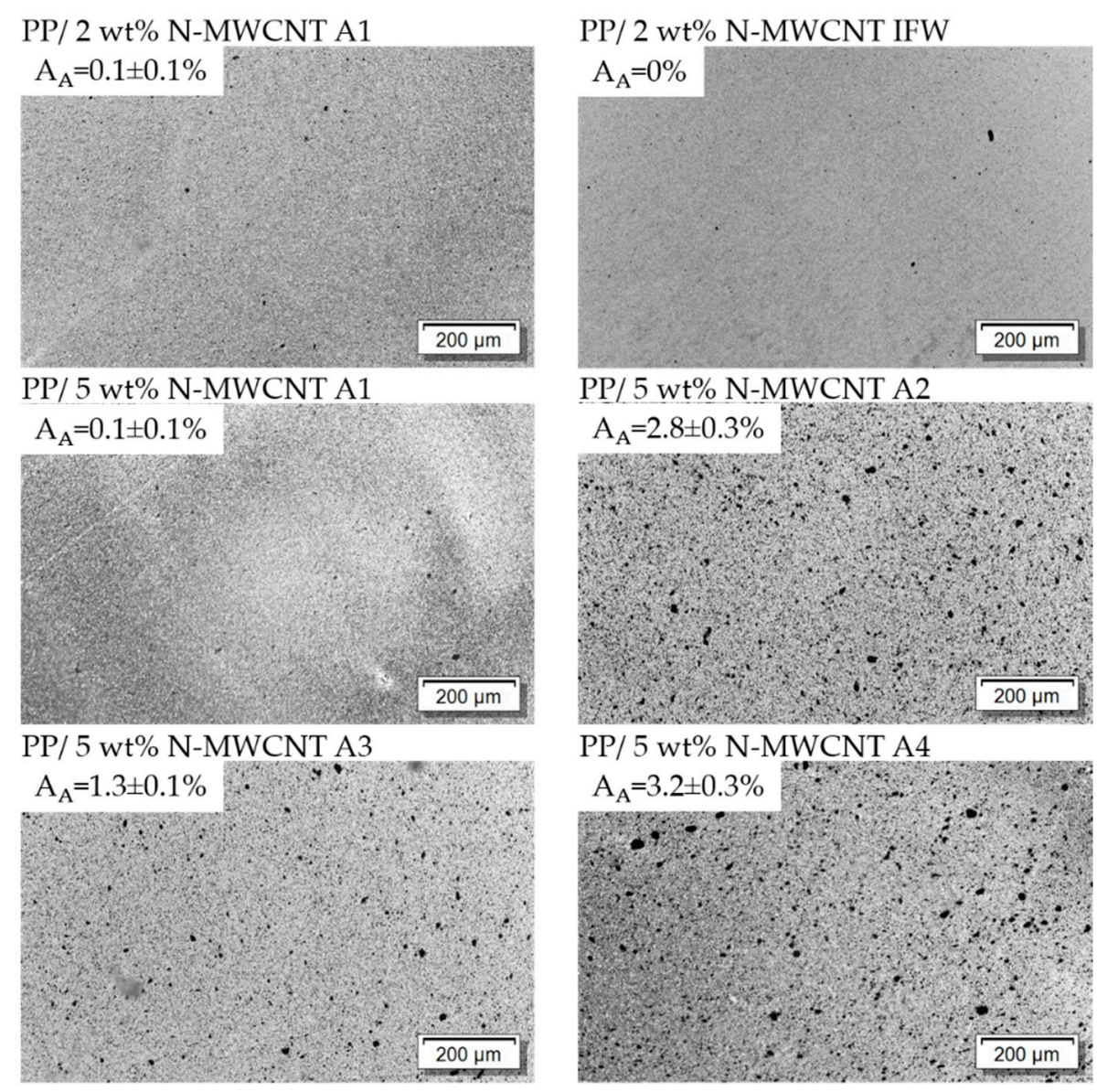

Figure 5. Transmission light microscopy images of thin sections of PP composites with N-MWCNTs, the insert shows the agglomerate area ratio $\mathrm{A}_{\mathrm{A}}$.

\subsection{Comparison of TE Properties of Composites with Buckypapers or Powder Packages of N-MWCNTs and Undoped CNTs}

In the present study, the n-type semi-conductive character of PP/N-MWCNT composites was presented indicated by negative Seebeck coefficients. Since both n- and p-type materials are needed in TE generators, undoped MWCNTs to prepare p-type composites were also incorporated in the study. For this comparison, commercially available MWCNTs and one SWCNT type were used. In addition, values of the PP composites were compared with those of buckypapers or powder packages of the nanotubes in order to see the changes connected with embedding the nanotubes in the polymer matrix. 
In Table 2, the thermoelectric properties of CNTs (prepared as buckypaper or powder) and their PP composites filled with $2 \mathrm{wt} \%$ or $5 \mathrm{wt} \%$ CNTs are summarized.

The Seebeck coefficients of all undoped CNTs, namely, Nanocyl NC7000, CNS-PEG, and Tuball, are positive, indicating a typical p-type character. Even if they differ slightly, the Seebeck coefficients of the respective powders and buckypapers are in the same range. Thereby, among the MWCNTs, CNS-PEG shows higher values than NC7000. SWCNTs Tuball have higher Seebeck coefficients than both MWCNTs. The PF values of the buckypapers are at least one order of magnitude higher than in the powder packages as the electrical conductivity is always significantly higher for buckypapers than powder packages, which is due to the denser packaging of neighboring CNTs in the buckypapers. After the incorporation of undoped CNTs in PP, positive Seebeck coefficients were measured. When comparing the Seebeck coefficient values of the buckypaper or powder and the composite, the $S$ values of the composite materials are always slightly higher. The significantly lower PF of PP composites than the buckypaper values is due to the significantly lower electrical conductivity of the composites, which is due to the increased electrical contact resistance after polymer chains wrap around the nanotubes.

For the N-doped MWCNTs, except for the powder sample of N-MWCNT A4, negative Seebeck coefficients in the range between $-11.6 \mu \mathrm{V} / \mathrm{K}$ and $-13.8 \mu \mathrm{V} / \mathrm{K}$ are measured. Interestingly, in contrast to the literature in which higher nitrogen contents were associated with higher $I_{\mathrm{D}} / I_{\mathrm{G}}$ ratios in RAMAN investigations [62], no such relationship could be found in our study. Furthermore, no clear correlation between $I_{\mathrm{D}} / I_{\mathrm{G}}$ ratio and the Seebeck coefficient could be found. Sample A3 with the lowest $\mathrm{I}_{\mathrm{D}} / \mathrm{I}_{\mathrm{G}}$ ratio showed the highest negative Seebeck coefficient of $-13.8 \mu \mathrm{V} / \mathrm{K}$ of the powder package, sample A4, which also has a low $I_{D} / I_{G}$ ratio, however, shows a positive Seebeck coefficient of $1.0 \mu \mathrm{V} / \mathrm{K}$. The positive Seebeck coefficient of N-MWCNT A4 is significantly lower compared to commercial undoped MWCNTs such as NC7000 or CNS-PEG. It can be concluded that the incorporation of nitrogen into N-MWCNT A4 initiates an electron-withdrawing effect without the MWCNTs reaching n-type character. Compared to N-MWCNT A1, the synthesis conditions were identical except for the catalyst used. For N-MWCNT A4 cobalt was applied instead of iron (see Table 1). It is assumed that the structural differences resulting from this variation, specifically the bamboo-like structure in A1 and the open channel structure in A4, determine the thermoelectric properties of the materials more than the higher nitrogen content in A4. This assumption should be investigated in further studies.

Negative Seebeck coefficients were generally determined in the PP/N-MWCNT composite materials, ranging from $-4.7 \mu \mathrm{V} / \mathrm{K}$ to $-22.8 \mu \mathrm{V} / \mathrm{K}$. Thereby, for the N-MWCNT type A, only the sample A1 gave sufficient high electrical conductivity at $2 \mathrm{wt} \%$ loading to measure Seebeck coefficients. For the samples A2-A4, $5 \mathrm{wt} \%$ loading was required to obtain measurable values. The N-MWCNT IFW showed higher values of electrical conductivity than those of the type A. However, the Seebeck coefficients were in the same range. The relatively high Seebeck coefficient of the buckypaper of N-MWCNT IFW, as taken from ref. [27], might be explained by the usage of a significant amount of comb-type polycarboxylate ether as dispersing agents. Moreover, a different measurement device was applied in [27]. Interestingly, a more negative Seebeck coefficient was achieved in most composites than in the corresponding buckypapers or powder packages. The only exception is N-MWCNT IFW, where slightly higher Seebeck coefficients were measured in the composite. Obviously, the surrounding polymer matrix somehow supports electron donation if the sample is exposed to the temperature gradient during the measurement of the Seebeck coefficient.

It can be concluded that the n-type character of the PP/N-MWCNT composites is due to the n-type character of the nanotubes, which arises from the nitrogen incorporated during synthesis. This conclusion is also confirmed by the investigations of Kumanek et al. [11] and Tzounis et al. [27]. Both studies showed that the doping of MWCNTs with nitrogen led to negative Seebeck coefficients both in the MWCNTs themselves and in the respective cellulose or cement composites. 
Table 2. Thermoelectric parameter of CNT buckypapers, powder packages and PP composites with $2 w t \%$ or $5 w t \%$ CNTs.

\begin{tabular}{|c|c|c|c|}
\hline Sample & $\begin{array}{c}\text { Volume Conductivity } \sigma \\
(\mathrm{S} / \mathrm{m})\end{array}$ & $\begin{array}{c}\text { Seebeck Coefficient } \\
\qquad S(\mu \mathrm{V} / \mathrm{K})\end{array}$ & $\begin{array}{r}\text { Power Factor } \\
P F\left(\mu \mathrm{W} / \mathrm{m} \cdot \mathrm{K}^{2}\right)\end{array}$ \\
\hline \multicolumn{4}{|c|}{ Undoped MWCNTs } \\
\hline NC7000 buckypaper [57] & 3125 & $8.0 \pm 0.0$ & 0.2015 \\
\hline NC7000 powder [57] & 417 & $6.3 \pm 0.0$ & 0.0165 \\
\hline $\mathrm{PP} / 2$ wt\% NC7000 [57] & 2 & $9.5 \pm 0.1$ & 0.0001 \\
\hline CNS-PEG buckypaper [57] & 9622 & $15.3 \pm 0.0$ & 2.2569 \\
\hline CNS PEG powder [57] & 933 & $10.1 \pm 0.0$ & 0.0949 \\
\hline PP/2 wt\% CNS-PEG [57] & 96 & $17.5 \pm 0.0$ & 0.0291 \\
\hline \multicolumn{4}{|c|}{ Undoped SWCNTs } \\
\hline Tuball buckypaper [57] & 42,227 & $37.4 \pm 0.9$ & 59.1933 \\
\hline Tuball powder [57] & 1790 & $39.6 \pm 0.2$ & 2.8094 \\
\hline $\mathrm{PP} / 2$ wt $\%$ Tuball [57] & 12 & $47.2 \pm 1.9$ & 0.0270 \\
\hline \multicolumn{4}{|c|}{ N-MWCNTs } \\
\hline N-MWCNT A1 powder [57] & 86 & $-11.6 \pm 0.1$ & 0.0117 \\
\hline $\mathrm{PP} / 2$ wt $\%$ N-MWCNT A1 & $8.3 \times 10^{-2}$ & $-17.3 \pm 0.4$ & $2.5 \times 10^{-5}$ \\
\hline $\mathrm{PP} / 5 \mathrm{wt} \%$ N-MWCNT A1 & 4 & $-15.9 \pm 0.1$ & $1.1 \times 10^{-3}$ \\
\hline N-MWCNT A2 powder & 250 & $-12.3 \pm 0.1$ & 0.0376 \\
\hline $\mathrm{PP} / 5$ wt $\%$ N-MWCNT A2 ${ }^{1}$ & $1.4 \times 10^{-2}$ & $-22.9 \pm 1.4$ & $7.1 \times 10^{-6}$ \\
\hline N-MWCNT A3 powder & 122 & $-13.8 \pm 0.4$ & 0.0233 \\
\hline $\mathrm{PP} / 5$ wt $\%$ N-MWCNT A3 ${ }^{1}$ & $2.5 \times 10^{-2}$ & $-18.8 \pm 2.2$ & $8.7 \times 10^{-6}$ \\
\hline N-MWCNT A4 powder & 340 & $1.0 \pm 0.0$ & 0.0003 \\
\hline $\mathrm{PP} / 5 \mathrm{wt} \% \mathrm{~N}-\mathrm{MWCNT} \mathrm{A} 4^{1}$ & $1.2 \times 10^{-1}$ & $-4.7 \pm 1.6$ & $2.6 \times 10^{-6}$ \\
\hline N-MWCNT IFW buckypaper [57] & 2196 & $-10.3 \pm 0.0$ & 0.2348 \\
\hline N-MWCNT IFW buckypaper ${ }^{2}$ [27] & 2748 & $-43 \pm 1.2$ & 5.081 \\
\hline N-MWCNT IFW powder [57] & 506 & $-12.7 \pm 0.1$ & 0.0812 \\
\hline PP/2 wt\% N-MWCNT IFW [57] & 10 & $-10.3 \pm 0.1$ & 0.0011 \\
\hline
\end{tabular}

${ }^{1}$ the composite with $2 \mathrm{wt} \%$ was not conductive enough for Seebeck coefficient measurements. ${ }^{2}$ CNTs were treated with a surfactant and another TE measurement equipment was used.

\subsection{Transient Absorption Spectroscopy (TAS) Measurement of PP Composites Filled with N-Doped or Undoped CNTs}

TAS measurements were performed in order to get a deeper understanding of the differences between $\mathrm{n}$ - and $\mathrm{p}$-type composites and their excitation decay behaviour. Figure 6a presents typical TAS spectra showing the difference in optical density $(\Delta \mathrm{OD})$ as a function of wavelength at various delay times for the $\mathrm{PP} / 2 \mathrm{wt} \%$ Tuball composite. A ground-state photo-bleaching negative $\Delta \mathrm{OD}$ peak at the vicinity of $760 \mathrm{~nm}$ is obtained. The $\Delta \mathrm{OD}$ profile reaches its maximum value after 0.2 ps from the photo-excitation point (at $0 \mathrm{ps}$ ). It is then found to continuously attenuate with time until it diminishes within several ps. It is noted that with the employed effluence of $14.7 \mathrm{~mJ} / \mathrm{cm}^{2}$, a reasonably good signal-to-noise ratio is achieved while ensuring the absence of ablation effect on the materials throughout the total duration of the measurement. Notably, the two nitrogen-doped samples PP/2 $w \mathrm{t} \%$ N-MWCNT A1 and PP/2 wt $\%$ N-MWCNT IFW exhibit similar spectra profiles (Figure S1) like the ones shown in Figure 6a for the undoped sample PP $/ 2 \mathrm{wt} \%$-Tuball. On the contrary, the pristine polypropylene polymer exhibits no photo-bleaching signal under equivalent excitation conditions (not shown here). This strongly implies that the obtained photo-bleaching for the polymer composites originates from the relaxation dynamics of the charged excitons within the incorporated carbon nanotubes.

In order to extract more information on the charge generation processes, the corresponding transient exciton dynamics for the three studied samples were considered and are displayed in Figure $6 \mathrm{~b}$. Inspection of Figure $6 \mathrm{~b}$ reveals that the PP/2 $\mathrm{wt} \%$ Tuball sample exhibits considerably slower exciton relaxation time, which is indicative of longer exciton lifetimes [37-40] when compared to samples PP $/ 2 \mathrm{wt} \% \mathrm{~N}-\mathrm{MWCNT} \mathrm{A} 1$ and $\mathrm{PP} / 2 \mathrm{wt} \% \mathrm{~N}-\mathrm{MWCNT}$ IFW. For the latter, two n-type samples, 
the free charge carriers (electrons) remain active for about 1 ps, while for the p-type PP/2 wt.\% tuball composite there are active free carriers (electron holes) even after 2.5 ps. Remarkably, the obtained free carrier lifetimes correlate well with the corresponding Seebeck coefficients of these composite materials. Specifically, the PP/2 wt \% Tuball exhibits the higher Seebeck coefficient $(47.2 \mu \mathrm{V} / \mathrm{K})$, while also showing a longer lifetime of the free charge carriers. This finding is rationalized plausibly if one considers that for this composite the carriers are available to diffuse for longer periods, and thus, assisting higher voltage generation and enhanced Seebeck coefficient. Moreover, this observation holds for the two nitrogen-doped samples PP/2 wt \% N-MWCNT A1 and PP/2 wt \% N-MWCNT IFW. Among these two n-type composites, the charged electron carriers in the former appear to have slightly longer lifetimes (Figure 6b), which could explain the obtained higher magnitude of the Seebeck coefficient, i.e., $-17.3 \mu \mathrm{V} / \mathrm{K}$ compared to $-10.3 \mu \mathrm{V} / \mathrm{K}$, respectively. Based on the above statements, it is found that nitrogen-doping accelerates the charged excitons recombination process of the electrons within the n-type composites, whereas the free-electron holes within the nitrogen-free p-type component tend to exist longer and favor the enhancement of charge generation and Seebeck coefficient.
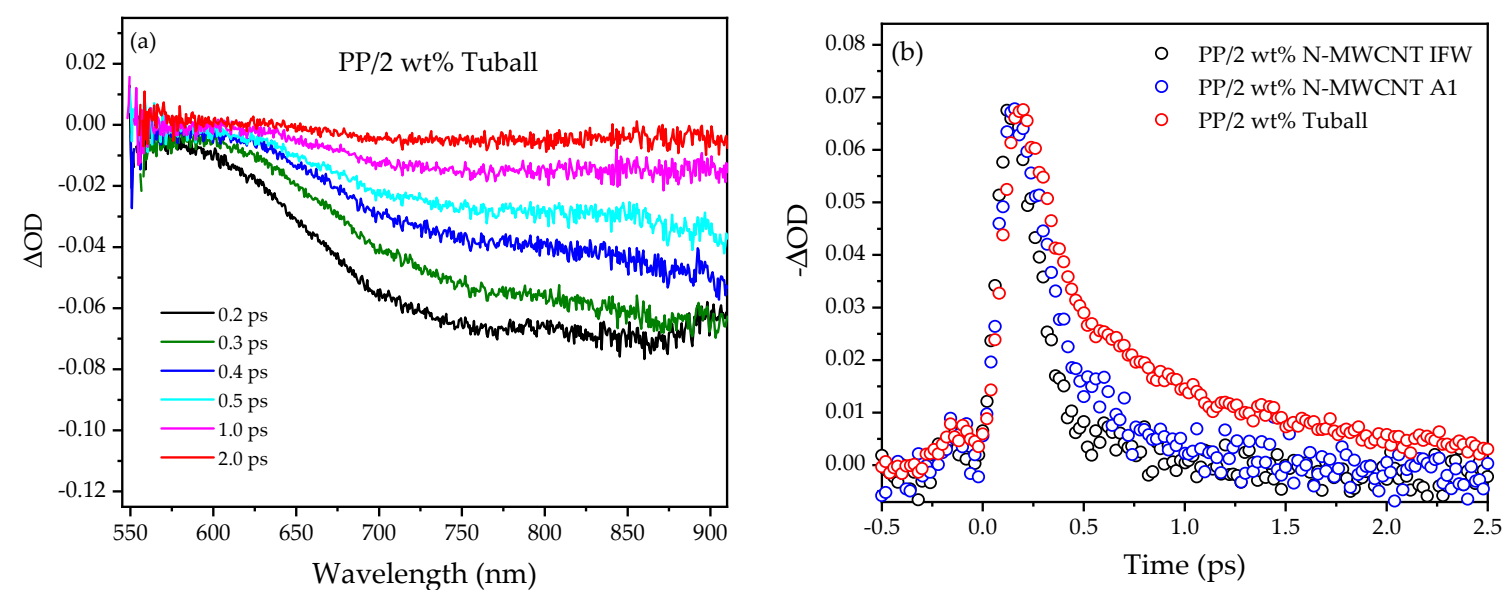

Figure 6. (a) Typical transient absorption spectroscopy (TAS) spectra of $\Delta \mathrm{OD}$ (difference in optical density) as a function of wavelength at various delay times for PP/2 wt\%-Tuball. (b) transient exciton dynamics of all studied samples following photoexcitation at $1026 \mathrm{~nm}$ with a pump effluence of 14.7 $\mathrm{mJ} / \mathrm{cm}^{2}$, probed at the maximum of $\Delta \mathrm{OD}$ at $810 \mathrm{~nm}, 760 \mathrm{~nm}$, and $760 \mathrm{~nm}$, for samples $\mathrm{PP} / 2 \mathrm{wt} \%$ N-MWCNT A1, PP/2 wt\% N-MWCNT IFW, and PP/2 wt\% Tuball, respectively.

\section{Discussion and Conclusions}

In summary, for the first time, the thermoelectric properties of nitrogen-doped MWCNTs in polypropylene-based melt-mixed nanocomposites were studied. The obtained values were compared with the corresponding TE properties of the N-MWCNT buckypapers or powder packages and with those of composites containing undoped CNTs.

The TE measurement on nitrogen-doped MWCNT powders (except the sample A4), as well as their corresponding buckypapers, showed negative Seebeck coefficients, meaning that these materials possess an n-type semi-conductive behavior. Due to the configuration of the nitrogen, it acts as an electron donor that drastically changes the semi-conducting behavior of the CNTs from a p-type hole conductor to an n-type electron conductor, which is reflected by a negative Seebeck coefficient. Typically, CNTs exhibit p-type behavior due to oxygen moieties withdrawing electrons to create holes. An exception was the sample N-MWCNT A4, which showed a significantly lower Seebeck coefficient than commercial undoped MWCNTs; however, it was still positive at $1 \mu \mathrm{V} / \mathrm{K}$. It was concluded that the inclusion of nitrogen in N-MWCNT A4 induced an electron-withdrawing effect without the MWCNTs achieving n-type character.

After incorporation of the MWCNTs into the PP matrix by melt mixing, the nanocomposites have a semiconductor behavior corresponding to their respective CNTs and even the composite containing 
the N-MWCNTs with the positive Seebeck sign became n-type. Except for A4, regardless of whether p-type or n-type CNT material is used, a correlation between the Seebeck coefficient sign of the CNT powders and the PP composites was observed. PP nanocomposites filled with p-type CNTs always had a positive $S$ coefficient, while PP nanocomposites filled with n-type MWCNTs had a negative $S$ coefficient. The higher is the Seebeck coefficient of the CNTs, the higher is the Seebeck coefficient of the PP composites. This clearly shows that the CNTs influence the TE properties of the composites. The lower Seebeck coefficient values (more negative values) of the n-type PP composites as compared to the corresponding powders/buckypapers indicate electron donation of the polymer to the N-MWCNTs. In contrast, the higher Seebeck coefficient values of the p-type PP composites as compared to the corresponding powder/buckypaper are a sign that the polymer matrix withdraws electrons from the undoped CNTs [57].

The comparison of the similarly produced N-doped MWCNTs A1-A4 shows that an interpretation of the results in terms of the nitrogen content is difficult and that obviously there is a complex interplay between different structural parameters of the nanotubes and their dispersion and network formation in the PP matrix. Despite the expectation that higher N content results in higher conductivity and Seebeck coefficient, the highest absolute Seebeck coefficient $(-22.9 \pm 1.4 \mu \mathrm{V} / \mathrm{K}$ at $5 \mathrm{wt} \% \mathrm{CNT})$ was observed for PP/N-MWCNT A2 (lowest N content with 0.41 at $\%$ ) and the lowest absolute Seebeck coefficient $(-4.7 \pm 1.6 \mu \mathrm{V} / \mathrm{K}$ at $5 \mathrm{wt} \% \mathrm{CNT}$ ) was measured for PP/N-MWCNT A4 (highest N content with 2.2 at $\%$ ). However, these N-MWCNT materials also differ in carbon purity, length, diameter, tube structure, agglomerate size and structure, and possibly other parameters not investigated. More detailed analysis is needed in the future to link structural nanotube parameters to the achieved Seebeck effect.

For PP composites filled with N-MWCNT IFW having a relatively high nitrogen content of 2.3 at $\%$, relatively low Seebeck coefficients of -9.7 to $-10.2 \mu \mathrm{V} / \mathrm{K}$ (at $1.5-4 \mathrm{wt} \% \mathrm{CNT}$ ) were determined. The highest power factor for this material was achieved with $4 \mathrm{wt} \% \mathrm{~N}-\mathrm{MWCNT}$ IFW where a suitable combination of high electrical conductivity and acceptable Seebeck coefficient led to a PF value of $6.1 \times 10^{-3} \mu \mathrm{W} /\left(\mathrm{m} \cdot \mathrm{K}^{2}\right)$. This is significantly lower than the best-achieved value of PP with $2 \mathrm{wt} \%$ undoped CNS-PEG, which reached $2.9 \times 10^{-2} \mu \mathrm{W} /\left(\mathrm{m} \cdot \mathrm{K}^{2}\right)$. However, with both N-MWCNT types used and possibly also with the undoped CNTs, a higher electrical conductivity and the resulting PF and ZT values can be expected with a further increase in the CNT content.

It is demonstrated that TAS is a powerful technique for exploring the differences between $\mathrm{p}$ and n-type composites and to differentiate the efficiency of different N-MWCNTs. In addition, the obtained TE performance and properties among the two N-doped MWCNTs correlate well with the corresponding transient exciton dynamics as probed by TAS. Namely, the lifetime of charged electron carriers in PP/N-MWCNT A1 was measured to be slightly longer when compared to PP/N-MWCNT IFW.

Supplementary Materials: The following are available online at http://www.mdpi.com/2504-477X/4/1/14/s1, Table S1: Electrical volume conductivity $\sigma$ of PP composites filled with N-MWCNT A1 or N-MWCNT IFW at different temperatures. Figure S1: Typical TAS spectra of $\triangle \mathrm{OD}$ as a function of wavelength at various delay times for (a) $\mathrm{PP} / 2$ wt $\%$ N-MWCNT A1 and (b) PP/2 wt \% N-MWCNT IFW.

Author Contributions: Conceptualization, P.P. and B.K.; methodology, P.P., B.K.; formal analysis, I.K., B.K.; investigation, R.F., M.L., M.A., M.K., B.K., I.K.; data curation, I.K., E.S. (Efthymis Serpetzoglou), B.K.; writing-original draft preparation, B.K.; writing—review and editing, P.P., M.L., S.H., R.F., U.S., M.A.; visualization, I.K., B.K.; supervision, E.S. (Emmanuel Stratakis), P.P.; project administration, P.P.; funding acquisition, E.S. (Emmanuel Stratakis), S.H., P.P. All authors have read and agreed to the published version of the manuscript.

Funding: The TAS measurements were funded by HELLAS-CH (MIS 5002735) Implemented under "Action for Strengthening Research and Innovation Infrastructures", funded by the Operational Programme "Competitiveness, Entrepreneurship and Innovation" (NSRF 2014-2020) and co-financed by Greece and the European Union (European Regional Development Fund). The preparation of nitrogen-doped-MWCNTs at the University of Calgary was funding by NSERC Discovery Grant no. 05503/2015. The preparation of nitrogen-doped-MWCNTs at the Leibniz-Institut für Festkörper- und Werkstoffforschung Dresden (IFW) was funded by the German Research Foundation (DFG) within Project No. LE 863/19-1.

Acknowledgments: The authors would like to thank the collaborators of the IPF research technology department for their support. 
Conflicts of Interest: The authors declare no conflict of interest. The funders had no role in the design of the study; in the collection, analyses, or interpretation of data; in the writing of the manuscript, or in the decision to publish the results.

\section{References}

1. Rowe, D.M. CRC Handbook of Thermoelectrics; CRC Press: Boca Raton, FL, USA, 1995.

2. Gayner, C.; Kar, K.K. Recent advances in thermoelectric materials. Prog. Mater. Sci. 2016, 83, 330-382. [CrossRef]

3. Caballero-Calero, O.; Martín-González, M. Thermoelectric nanowires: A brief prospective. Scr. Mater. 2016, 111, 54-57. [CrossRef]

4. Poudel, B.; Hao, Q.; Ma, Y.; Lan, Y.; Minnich, A.; Yu, B.; Yan, X.; Wang, D.; Muto, A.; Vashaee, D.; et al. High-thermoelectric performance of nanostructured bismuth antimony telluride bulk alloys. Science 2008, 320, 634-638. [CrossRef] [PubMed]

5. McGrail, B.T.; Sehirlioglu, A.; Pentzer, E. Polymer composites for thermoelectric applications. Angew. Chem. Int. Ed. 2015, 54, 1710-1723. [CrossRef]

6. Collins, P.G.; Bradley, K.; Ishigami, M.; Zettl, A. Extreme oxygen sensitivity of electronic properties of carbon nanotubes. Science 2000, 287, 1801-1804. [CrossRef]

7. Liebscher, M.; Gärtner, T.; Tzounis, L.; Mičušík, M.; Pötschke, P.; Stamm, M.; Heinrich, G.; Voit, B. Influence of the MWCNT surface functionalization on the thermoelectric properties of melt-mixed polycarbonate composites. Compos. Sci. Technol. 2014, 101, 133-138. [CrossRef]

8. Tzounis, L.; Gartner, T.; Liebscher, M.; Pötschke, P.; Stamm, M.; Voit, B.; Heinrich, G. Influence of a cyclic butylene terephthalate oligomer on the processability and thermoelectric properties of polycarbonate/ MWCNT nanocomposites. Polymer 2014, 55, 5381-5388. [CrossRef]

9. Latil, S.; Roche, S.; Mayou, D.; Charlier, J.-C. Mesoscopic transport in chemically doped carbon nanotubes. Phys. Rev. Lett. 2004, 92, 256805. [CrossRef]

10. Terrones, M.; Ajayan, P.M.; Banhart, F.; Blase, X.; Carroll, D.L.; Charlier, J.C.; Czerw, R.; Foley, B.; Grobert, N.; Kamalakaran, R.; et al. N-doping and coalescence of carbon nanotubes: Synthesis and electronic properties. Appl. Phys. A 2002, 74, 355-361. [CrossRef]

11. Kumanek, B.; Stando, G.; Wróbel, P.S.; Krzywiecki, M.; Janas, D. Thermoelectric properties of composite films from multi-walled carbon nanotubes and ethyl cellulose doped with heteroatoms. Synth. Met. 2019, 257, 116190. [CrossRef]

12. Brownlie, L.; Shapter, J. Advances in carbon nanotube n-type doping: Methods, analysis and applications. Carbon 2018, 126, 257-270. [CrossRef]

13. Dörling, B.; Sandoval, S.; Kankla, P.; Fuertes, A.; Tobias, G.; Campoy-Quiles, M. Exploring different doping mechanisms in thermoelectric polymer/carbon nanotube composites. Synth. Met. 2017, 225, 70-75. [CrossRef]

14. Piao, M.; Alam, M.R.; Kim, G.; Dettlaff-Weglikowska, U.; Roth, S. Effect of chemical treatment on the thermoelectric properties of single walled carbon nanotube networks. Phys. Status Solidi B 2012, 249, 2353-2356. [CrossRef]

15. Ryu, Y.; Freeman, D.; Yu, C. High electrical conductivity and n-type thermopower from double-/single-wall carbon nanotubes by manipulating charge interactions between nanotubes and organic/inorganic nanomaterials. Carbon 2011, 49, 4745-4751. [CrossRef]

16. Liu, Y.; Nitschke, M.; Stepien, L.; Khavrus, V.; Bezugly, V.; Cuniberti, G. Ammonia plasma-induced n-type doping of semiconducting carbon nanotube films: Thermoelectric properties and ambient effects. ACS Appl. Mater. Interfaces 2019, 11, 21807-21814. [CrossRef] [PubMed]

17. Ayala, P.; Arenal, R.; Rümmeli, M.; Rubio, A.; Pichler, T. The doping of carbon nanotubes with nitrogen and their potential applications. Carbon 2010, 48, 575-586. [CrossRef]

18. Kim, S.Y.; Lee, J.; Na, C.W.; Park, J.; Seo, K.; Kim, B. N-doped double-walled carbon nanotubes synthesized by chemical vapor deposition. Chem. Phys. Lett. 2005, 413, 300-305. [CrossRef]

19. Boncel, S.; Pattinson, S.W.; Geiser, V.; Shaffer, M.S.P.; Koziol, K.K.K. En route to controlled catalytic CVD synthesis of densely packed and vertically aligned nitrogen-doped carbon nanotube arrays. Beilstein J. Nanotechnol. 2014, 5, 219-233. [CrossRef] 
20. Sharifi, T.; Nitze, F.; Barzegar, H.R.; Tai, C.-W.; Mazurkiewicz, M.; Malolepszy, A.; Stobinski, L.; Wagberg, T. Nitrogen doped multi walled carbon nanotubes produced by CVD-correlating xps and Raman spectroscopy for the study of nitrogen inclusion. Carbon 2012, 50, 3535-3541. [CrossRef]

21. Fuge, R.; Liebscher, M.; Schröfl, C.; Oswald, S.; Leonhardt, A.; Büchner, B.; Mechtcherine, V. Fragmentation characteristics of undoped and nitrogen-doped multiwalled carbon nanotubes in aqueous dispersion in dependence on the ultrasonication parameters. Diam. Relat. Mater. 2016, 66, 126-134. [CrossRef]

22. Arjmand, M.; Chizari, K.; Krause, B.; Pötschke, P.; Sundararaj, U. Effect of synthesis catalyst on structure of nitrogen-doped carbon nanotubes and electrical conductivity and electromagnetic interference shielding of their polymeric nanocomposites. Carbon 2016, 98, 358-372. [CrossRef]

23. Czerw, R.; Terrones, M.; Charlier, J.C.; Blase, X.; Foley, B.; Kamalakaran, R.; Grobert, N.; Terrones, H.; Tekleab, D.; Ajayan, P.M.; et al. Identification of electron donor states in n-doped carbon nanotubes. Nano Lett. 2001, 1, 457-460. [CrossRef]

24. Kang, H.S.; Jeong, S. Nitrogen doping and chirality of carbon nanotubes. Phys. Rev. B 2004, 70, 233411. [CrossRef]

25. Rocha, A.R.; Padilha, J.E.; Fazzio, A.; da Silva, A.J.R. Transport properties of single vacancies in nanotubes. Phys. Rev. B 2008, 77, 153406. [CrossRef]

26. Eckert, V.; Leonhardt, A.; Hampel, S.; Büchner, B. Morphology of MWCNT in dependence on n-doping, synthesized using a sublimation-based CVD method at $750{ }^{\circ} \mathrm{C}$. Diam. Relat. Mater. 2018, 86, 8-14. [CrossRef]

27. Tzounis, L.; Liebscher, M.; Fuge, R.; Leonhardt, A.; Mechtcherine, V. P- and n-type thermoelectric cement composites with CVD grown p- and n-doped carbon nanotubes: Demonstration of a structural thermoelectric generator. Energy Build. 2019, 191, 151-163. [CrossRef]

28. Ewels, C.P.; Glerup, M. Nitrogen doping in carbon nanotubes. J. Nanosci. Nanotechnol. 2005, 5, 1345-1363. [CrossRef]

29. Cruz-Silva, E.; Cullen, D.A.; Gu, L.; Romo-Herrera, J.M.; Muñoz-Sandoval, E.; López-Urías, F.; Sumpter, B.G.; Meunier, V.; Charlier, J.-C.; Smith, D.J.; et al. Heterodoped nanotubes: Theory, synthesis, and characterization of phosphorus-nitrogen doped multiwalled carbon nanotubes. ACS Nano 2008, 2, 441-448. [CrossRef]

30. Sobolkina, A.; Mechtcherine, V.; Bellmann, C.; Khavrus, V.; Oswald, S.; Hampel, S.; Leonhardt, A. Surface properties of CNTs and their interaction with silica. J. Colloid Interface Sci. 2014, 413, 43-53. [CrossRef]

31. Konidakis, I.; Maksudov, T.; Serpetzoglou, E.; Kakavelakis, G.; Kymakis, E.; Stratakis, E. Improved charge carrier dynamics of $\mathrm{CH} 3 \mathrm{NH} 3 \mathrm{PBI} 3$ perovskite films synthesized by means of laser-assisted crystallization. ACS Appl. Energy Mater. 2018, 1, 5101-5111. [CrossRef]

32. Chochos, C.L.; Leclerc, N.; Gasparini, N.; Zimmerman, N.; Tatsi, E.; Katsouras, A.; Moschovas, D.; Serpetzoglou, E.; Konidakis, I.; Fall, S.; et al. The role of chemical structure in indacenodithienothiophene-alt-benzothiadiazole copolymers for high performance organic solar cells with improved photo-stability through minimization of burn-in loss. J. Mater. Chem. A 2017, 5, 25064-25076. [CrossRef]

33. Serpetzoglou, E.; Konidakis, I.; Maksudov, T.; Panagiotopoulos, A.; Kymakis, E.; Stratakis, E. In situ monitoring of the charge carrier dynamics of $\mathrm{CH} 3 \mathrm{NH} 3 \mathrm{PBI} 3$ perovskite crystallization process. J. Mater. Chem. C 2019, 7, 12170. [CrossRef]

34. Dal Conte, S.; Vidmar, L.; Golež, D.; Mierzejewski, M.; Soavi, G.; Peli, S.; Banfi, F.; Ferrini, G.; Comin, R.; Ludbrook, B.M.; et al. Snapshots of the retarded interaction of charge carriers with ultrafast fluctuations in cuprates. Nat. Phys. 2015, 11, 421. [CrossRef]

35. Wang, H.; Zhang, C.; Rana, F. Ultrafast dynamics of defect-assisted electron-hole recombination in monolayer $\mathrm{MoS}_{2}$. Nano Lett. 2015, 15, 339-345. [CrossRef] [PubMed]

36. Konidakis, I.; Skoulas, E.; Papadopoulos, A.; Serpetzoglou, E.; Margariti, E.; Stratakis, E. Erasable and rewritable laser-induced gratings on silver phosphate glass. Appl. Phys. A 2018, 124, 839. [CrossRef]

37. Styers-Barnett, D.J.; Ellison, S.P.; Mehl, B.P.; Westlake, B.C.; House, R.L.; Park, C.; Wise, K.E.; Papanikolas, J.M. Exciton dynamics and biexciton formation in single-walled carbon nanotubes studied with femtosecond transient absorption spectroscopy. J. Phys. Chem. C 2008, 112, 4507-4516. [CrossRef]

38. Ruzicka, B.A.; Wang, R.; Lohrman, J.; Ren, S.; Zhao, H. Exciton diffusion in semiconducting single-walled carbon nanotubes studied by transient absorption microscopy. Phys. Rev. B 2012, 86, 205417. [CrossRef] 
39. Soavi, G.; Scotognella, F.; Brida, D.; Hefner, T.; Späth, F.; Antognazza, M.R.; Hertel, T.; Lanzani, G.; Cerullo, G. Ultrafast charge photogeneration in semiconducting carbon nanotubes. J. Phys. Chem. C 2013, 117, 10849-10855. [CrossRef]

40. Bai, Y.; Olivier, J.-H.; Bullard, G.; Liu, C.; Therien, M.J. Dynamics of charged excitons in electronically and morphologically homogeneous single-walled carbon nanotubes. Proc. Natl. Acad. Sci. USA 2018, 115, 674-679. [CrossRef]

41. Luo, J.; Cerretti, G.; Krause, B.; Zhang, L.; Otto, T.; Jenschke, W.; Ullrich, M.; Tremel, W.; Voit, B.; Pötschke, P. Polypropylene-based melt mixed composites with singlewalled carbon nanotubes for thermoelectric applications: Switching from p-type to n-type by the addition of polyethylene glycol. Polymer 2017, 108, 513-520. [CrossRef]

42. Luo, J.; Krause, B.; Pötschke, P. Melt-mixed thermoplastic composites containing carbon nanotubes for thermoelectric applications. Aims Mater. Sci. 2016, 3, 1107-1116. [CrossRef]

43. Luo, J.; Krause, B.; Pötschke, P. Polymer-carbon nanotube composites for thermoelectric applications. Aip Conf. Proc. 2017, 1914, 030001.

44. Pötschke, P.; Krause, B.; Luo, J. Melt mixed composites of polypropylene with singlewalled carbon nanotubes for thermoelectric applications: Switching from $\mathrm{p}$ - to $\mathrm{n}$-type behavior by additive addition. Aip Conf. Proc. 2019, 2055, 090004.

45. Paleo, A.J.; Vieira, E.M.F.; Wan, K.; Bondarchuk, O.; Cerqueira, M.F.; Goncalves, L.M.; Bilotti, E.; Alpuim, P.; Rocha, A.M. Negative thermoelectric power of melt mixed vapor grown carbon nanofiber polypropylene composites. Carbon 2019, 150, 408-416. [CrossRef]

46. Pawar, S.P.; Arjmand, M.; Pötschke, P.; Krause, B.; Fischer, D.; Bose, S.; Sundararaj, U. Tuneable dielectric properties derived from nitrogen-doped carbon nanotubes in PVDF-based nanocomposites. ACS Omega 2018, 3, 9966-9980. [CrossRef]

47. Technical Data Sheet: NC7000 ${ }^{\mathrm{TM}}$, v08, 12 July 2016; Nanocyl: Sambreville, Belgium, 2007; Available online: https://www.nanocyl.com/wp-content/uploads/2016/07/DM-TI-02-TDS-NC7000-V08.pdf (accessed on 10 December 2019).

48. Castillo, F.Y.; Socher, R.; Krause, B.; Headrick, R.; Grady, B.P.; Prada-Silvy, R.; Pötschke, P. Electrical, mechanical, and glass transition behavior of polycarbonate-based nanocomposites with different multi-walled carbon nanotubes. Polymer 2011, 52, 3835-3845. [CrossRef]

49. Krause, B.; Boldt, R.; Pötschke, P. A method for determination of length distributions of multiwalled carbon nanotubes before and after melt processing. Carbon 2011, 49, 1243-1247. [CrossRef]

50. Chen, L.; Ozisik, R.; Schadler, L.S. The influence of carbon nanotube aspect ratio on the foam morphology of MWNT/PMMA nanocomposite foams. Polymer 2010, 51, 2368-2375. [CrossRef]

51. Krause, B.; Barbier, C.; Kunz, K.; Pötschke, P. Comparative study of singlewalled, multiwalled, and branched carbon nanotubes melt mixed in different thermoplastic matrices. Polymer 2018, 159, 75-85. [CrossRef]

52. TuballTM Graphene Nanotubes. Available online: https://tuball.com/en/about-tuball (accessed on 16 September 2019).

53. Krause, B.; Pötschke, P.; Ilin, E.; Predtechenskiy, M. Melt mixed SWCNT-polypropylene composites with very low electrical percolation. Polymer 2016, 98, 45-50. [CrossRef]

54. Krestinin, A.V.; Dremova, N.N.; Knerel'man, E.I.; Blinova, L.N.; Zhigalina, V.G.; Kiselev, N.A. Characterization of SWCNT products manufactured in Russia and the prospects for their industrial application. Nanotechnol. Russ. 2015, 10, 537-548. [CrossRef]

55. Gnanaseelan, M.; Chen, Y.; Luo, J.; Krause, B.; Pionteck, J.; Pötschke, P.; Qi, H. Cellulose-carbon nanotube composite aerogels as novel thermoelectric materials. Compos. Sci. Technol. 2018, 163, 133-140. [CrossRef]

56. Jenschke, W.; Ullrich, M.; Krause, B.; Pötschke, P. Messanlage zur Untersuchung des Seebeck-Effektes in Polymermaterialien-Measuring apparatus for study of Seebeck-effect in polymer materials. Tech. Mess. 2020, 87. [CrossRef]

57. Krause, B.; Barbier, C.; Levente, J.; Klaus, M.; Pötschke, P. Screening of different carbon nanotubes in melt-mixed polymer composites with different polymer matrices for their thermoelectric properties. J. Compos. Sci. 2019, 3, 106. [CrossRef]

58. Rzeczkowski, P.; Krause, B.; Pötschke, P. Characterization of highly filled PP/graphite composites for adhesive joining in fuel cell applications. Polymers 2019, 11, 462. [CrossRef] [PubMed] 
59. Krause, B.; Pötschke, P. Electrical and thermal conductivity of polypropylene filled with combinations of carbon fillers. Aip Conf. Proc. 2016, 1779, 040003.

60. Shklovskii, B.I.; Efros, A.L. Variable-range hopping conduction. In Electronic Properties of Doped Semiconductors; Springer: Berlin/Heidelberg, Germany, 1984; pp. 202-227.

61. Kasaliwal, G.R.; Pegel, S.; Göldel, A.; Pötschke, P.; Heinrich, G. Analysis of agglomerate dispersion mechanisms of multiwalled carbon nanotubes during melt mixing in polycarbonate. Polymer 2010, 51, 2708-2720. [CrossRef]

62. Bulusheva, L.G.; Okotrub, A.V.; Kinloch, I.A.; Asanov, I.P.; Kurenya, A.G.; Kudashov, A.G.; Chen, X.; Song, H. Effect of nitrogen doping on Raman spectra of multi-walled carbon nanotubes. Phys. Status Solidi B 2008, 245, 1971. [CrossRef]

(C) 2020 by the authors. Licensee MDPI, Basel, Switzerland. This article is an open access article distributed under the terms and conditions of the Creative Commons Attribution (CC BY) license (http://creativecommons.org/licenses/by/4.0/). 